\section{Más allá de la discapacidad: reflexiones en torno a la relatividad de la organización sensorial}

\author{
Beyond disability: reflexions on the relativity \\ of sensory organization
}

\section{Resumen}

En el presente artículo haremos un breve recorrido histórico y antropológico por algunas de las formas en las que la percepción sensorial ha sido concebida, algo que se encuentra íntimamente ligado a las particularidades de cada cultura, que ejerce su influencia en las formas individuales de percibir y, por consiguiente, en la definición de lo que es o no una discapacidad como ocurre en lo que convencionalmente se denomina cultura occidental con el caso de la discapacidad visual, dada la primacía actual del sentido de la vista sobre los demás sentidos.

Asimismo, intentaremos replantear el concepto de discapacidad a favor de términos como el de diversidad funcional, que implica una forma más amplia de concebir la variabilidad de percibir la realidad, en virtud de la enorme plasticidad del ser humano, capaz de convertir lo que a primera vista puede parecer tan sólo una limitación física en un original desarrollo de nuevas habilidades.

Palabras clave

Percepción sensorial, relativismo, discapacidad, discapacidad visual.

\section{Abstract}

This article offers a historical and anthropological review of different ways of conceiving sensory perception, which are intimately linked to cultural characteristics-. Culture influences individual perception and, consequently, the definition of what is or is not a disability, as it happens with visual impairment in what we call Western culture, given the current primacy of the visual over other senses.

Furthermore, we will try to rethink the concept of disability in favor of terms such as functional diversity, which involves a broader conception of the various ways of perceiving reality, because of the enormous plasticity of the human being, who is able to turn what at a first glance may seem just a physical limitation into an original development of new skills.

\section{Key words}

Sensory perception, relativism disability, visual impairment.

\section{Susana Rodríguez Díaz <srodriguez@madrid.uned.es> \\ Universidad Nacional de Educación a Distancia}

Para citar:

Rodríguez Díaz, S. (20I3): “Más allá de la discapacidad: reflexiones en torno a la relatividad de la organización sensorial". Revista Española de Discapacidad, I (2): 5I-58.

<http://dx.doi.org/IO.5569/23405 I04.01.02.03>

Fecha de recepción: 4-I I-2OI2 Fecha de aceptación: 4-I I-20I3 


\section{Introducción}

Esta reflexión se encuentra en íntima conexión con planteamientos como el de Ferrante y Ferreira (20II) en torno a la necesidad de trascender ciertas formas institucionalizadas de acercamiento a la problemática de la discapacidad. Por ello, en las páginas que siguen intentaremos abrir nuevas posibilidades a la hora de comprender y vivir la discapacidad, para lo cual nos situaremos en un relativismo cultural y cognitivo que, esperamos, enriquezca los desarrollos actuales.

Lo primero que conviene aclarar es que la distinción entre "capacidad" y "discapacidad" es una construcción social históricamente determinada que tiene su origen en principios culturales concretos, así como en una naturalización de la normalidad. Al calificar a un determinado individuo o grupo de personas como "dis-capacitados" la etiqueta acaba por adueñarse de su identidad entera, lo que les lleva a ser discriminados en virtud de ciertas irregularidades que parecen afectar a la persona en su conjunto.

En efecto, la conceptualización actual de la discapacidad arranca de un proceso modernizador que supone la aplicación de un modelo normativo que implica la definición de los usos y presentaciones del cuerpo humano desde un contexto que lo reclama como fuerza de trabajo, y que tienen que responder a unos estándares estéticos y de salud. Frente a un modelo mecanicista que trata a la persona como máquina cuyas piezas se pueden (o no) reparar, probaremos a pensar en cada ser humano como organismo singular dotado de múltiples potencialidades.

Para plantear la cuestión de las diferencias y singularidades corporales más allá de la noción contemporánea de discapacidad haremos un recorrido por distintas visiones del cuerpo, sus usos y capacidades desde un punto de vista histórico y antropológico, mostrando así cómo la visión de lo que es normal y, por ende, lo patológico, no es universal ni está en la esencia de lo humano, sino que es provisional, transitoria y variable. Asimismo, la exploración en torno a la relatividad de la percepción sensorial nos permitirá cuestionar términos como el de "discapacidad" a favor de nociones como la de "diversidad funcional" (véase Rodríguez Díaz y Ferreira, 2008 y 2010).

En un primer momento, abordaremos brevemente el tema de la variabilidad cultural e histórica de la organización sensorial, deteniéndonos en la primacía que, en la cultura occidental actual, se concede al sentido de la vista, así como la constitución de determinadas maneras de mirar en detrimento de otras. A continuación, replantearemos la habitual manera de concebir la discapacidad visual como mera carencia física a favor de una forma más amplia de entender la variabilidad de las formas de ser humano y la enorme plasticidad del cerebro, capaz de desarrollar nuevas habilidades en determinadas circunstancias.

\section{Variabilidad cultural e histórica de la organización sensorial}

Para desarrollar este breve recorrido recurriremos a autores como David Le Breton, para quien la percepción es, en realidad, una interpretación. No existen "verdades” sobre las cosas, sino múltiples percepciones que dependen del punto de vista y las expectativas, así como de la adscripción social y cultural: "La percepción no es la realidad, sino la manera de sentir la realidad" (Le Breton, 2007: 25). Para MerleauPonty (I984), la cosa nunca puede ser separada del que la percibe, ya que toda percepción es comunión, comunicación.

Por su parte, Walter Ong (I97I) señala cómo cada sociedad genera su particular organización sensorial lo que supone que, frente a multitud de experiencias sensoriales posibles, un grupo humano define maneras de seleccionar, planteando sistemas de significados y valores. 
Puede hablarse, pues, de una educación de los sentidos. Además, existe una sutil dialéctica entre lengua y percepción. "Por eso, de un extremo a otro del mundo, los hombres no ven, no huelen, no gustan, no oyen, no tocan las mismas cosas de la misma manera, así como no experimentan las mismas emociones" (Le Breton, 2007: 24).

Constance Classen (I993) estudia las diferencias culturales a la hora de dotar de sentido al mundo, lo que conduce a distintos modos de conciencia. A pesar de que en la cultura occidental se suele pensar en la percepción como en un acto físico y no cultural, considerando que existen cinco sentidos (vista, oído, tacto, olfato y gusto), para otras culturas hay más sentidos y para otras, menos. Incluso en Occidente no siempre ha habido acuerdo en el número de sentidos, y la jerarquía de éstos ha ido experimentando variaciones con el paso del tiempo. De hecho, en los últimos años, el interés científico en la percepción ha llevado a cuestionar la tradicional división en cinco sentidos. El tacto se ha dividido en multitud de sentidos (kinestesia, temperatura, dolor); además, existe un sentido magnético, así como una relación entre sentidos y emociones.

Walter Ong (I97I), entre otros autores, ha sugerido que el orden sensorial revela un orden social y cultural. De este modo, las sociedades en las que prima el olor tienden a desplegar rasgos culturales como la preferencia por la apariencia sobre la sustancia, la espiritualidad sobre el materialismo, la síntesis sobre el análisis. En el Occidente moderno, los olores tienden a ser silenciados a favor de un visualismo que conlleva un modo de pensamiento objetivo, lineal, analítico y fragmentado, conduciendo a la despersonalización, individualismo, división del trabajo, así como separación de sentidos, funciones, operaciones y tareas.

El progresivo auge del ojo ha sido estudiado por Simmel (I977) -que analiza su relación con la reducción de las relaciones personales en la gran ciudad-y por Foucault (2000) -que considera que el desarrollo de la vista ha determinado el surgimiento de modos de control en instituciones públicas como escuelas o prisiones, designadas para la vigilancia constante (panoptismo)-. La vista es, además, el sentido de la ciencia; racionalistas y empiristas proponen un modelo del universo a base de mapas, diagramas y esquemas. La vista distancia al espectador del espectáculo (objetividad), sostenido en un punto de vista (condicionado por la visión).

\section{La primacía occidental del sentido de la} vista

Como ya se ha apuntado, los seres humanos viven sensorialidades diferentes según su educación e historia vital. En Occidente se ha valorado mucho el oído y la vista; sin denigrar lo visual, en la tradición judía y cristiana la audición era fundamental, pues la palabra de Dios se escuchaba. Para filósofos como Platón el distanciamiento de la sensorialidad ordinaria y su ascenso al mundo de las Ideas se realizaba bajo la égida de lo visual. Lo mismo sucede con Aristóteles, para quien la vista es un sentido privilegiado.

El privilegio de la vista prosigue su camino a lo largo de los siglos. Durante mucho tiempo el modelo visual fue el que se estableció en el quattrocento mediante la perspectiva, forma simbólica que constituye una manera de captar la realidad mediante un dispositivo de simulación que parece duplicarla y que separa al sujeto del objeto (Panofsky, I975).

La difusión de la imprenta a partir del siglo XVI, los descubrimientos ópticos a comienzos del XVII junto con el advenimiento de los modernos procedimientos de observación científica indican una transformación de las maneras de ver y pensar la mirada (Le Breton, 2007). En el siglo XIX, su primacía sobre los demás sentidos en términos de civilización y conocimiento es un lugar común en todas las ciencias. La preponderancia de la vista impregna también las relaciones sociales. Ya a comienzos 
de siglo, Simmel (I977) señalaba cómo la ciudad consistía una disposición de lo visual y una proliferación de lo visible.

La penetración de la vista se ha ido acentuando $\mathrm{y}$, en la actualidad, vemos menos al mundo con nuestros propios ojos que a través de innumerables pantallas. El espectáculo encuentra en la vista al sentido humano privilegiado, como apunta Debord (2005). Además, como advierte Baudrillard (2002), las imágenes avanzan sobre lo real; la copia sobresale con respecto al original, que sólo tiene el valor que le otorga la copia. El mapa precede al territorio; ya no existe lo real, sino lo hiperreal.

Las técnicas de vigilancia mediante cámaras instauran una vista superlativa que excede la simple mirada gracias a dispositivos tecnológicos. Por ello, para Foucault (2000), nuestra sociedad no es la del espectáculo, sino la de la vigilancia. Sin embargo, espectáculo y vigilancia no son contradictorios, existiendo una hipertrofia de la mirada que consolida ciertas maneras de ver y niega otras.

En efecto, para Christian Ferrer (2000: 2629), la orientación sensorial visual determina la existencia de un "ojo orientado". Un conjunto de instituciones y de tecnologías están siendo dispuestas para orientar la atención visual, señalando perspectivas convenientes, y haciendo invisibles objetos y actividades visuales inconvenientes. Se trata de un "ocularcentrismo"; esto es, un sistema de orientación y coerción visual efectuado a través de actividades visuales cotidianas. Esto remite más a la incapacidad para construir otras visibilidades que al problema de la censura.

La alternativa, para Ferrer (2000: I I), consiste en ampliar las fronteras del conocimiento e intensificar el placer visual, cultivando la "artesanía ocular": "Creo que a la vista pueden serle restituidas capacidades visionarias que son continuamente escamoteadas por su acostumbramiento a las operaciones perspectivas rutinarias”.

\section{Replanteando la discapacidad visual}

Siguiendo con este planteamiento, podría decirse entonces que eso que llamamos "normalidad" a la hora de utilizar el sentido de la vista es, en realidad, una forma socialmente institucionalizada de percibir e interpretar la realidad, que además excluye formas alternativas. Como apuntaba Canguilhem (I970: I87-I93), la norma sirve para unificar la diversidad; lo diferente es rechazado. La normalización siempre implica un otro excluido. A esto hay que añadir que lo normal se fija a partir de una decisión normativa y que son unas clases concretas las que tienen la capacidad de establecer normas sociales.

Esto conduciría, por una parte, a un reconocimiento de que lo que se denomina discapacidad depende directamente de esa decisión normativa, como ya apuntábamos al comienzo del presente ensayo; en las sociedades contemporáneas, las directrices normalizadoras son estipuladas por la ciencia médica, que establece un vínculo entre discapacidad y enfermedad; esto es, desviación de la norma de salud. Si lo que se considera una salud normal varía culturalmente, parece bastante claro que en la cultura occidental esta definición está sujeta a demandas de funcionalidad y eficiencia.

Al ser la vista el sentido más solicitado en la vida social, la discapacidad visual es, por ende, una anomalía y una invalidez (y no sólo ésta, sino otras formas de percepción visual, aquellas que no encajen en lo considerado como "normal"). Sin embargo, las mitologías culturales a menudo confieren al ciego la facultad de la videncia, según apunta Ferrer (2000). En la mitología griega existe la figura de Tiresias, que fue castigado con la ceguera por ver a Atenea bañándose pero al que, a cambio, se concedió el don de la profecía. A Edipo se le castigó por sus crímenes arrancándole los ojos, pero se vuelve sabio. Filósofos como Sócrates consideraban que los ojos del pensamiento sólo comenzaban a tener una mirada penetrante cuando la visión de los ojos perdía su agudeza; para Plotino 
quien pierde la vista se beneficia con una mirada volcada hacia el interior, accediendo a un mundo invisible a los demás.

La ceguera, en estos casos, no se presenta como limitación sino como apertura a la capacidad de ver más allá de lo visible. La videncia perfora el caparazón de las cosas (revelación) y atraviesa límites temporales. La videncia ilumina más allá de lo sensible.

En este punto de nuestra reflexión puede ser de interés recurrir a la obra del neurólogo Oliver Sacks, que hace hincapié en la capacidad del ser humano de reinventarse ante circunstancias difíciles. El cerebro no es un órgano pasivo ni meramente reactivo, sino una compleja trama de potencialidades que se activan o inhiben en función de las circunstancias y de su propia dinámica, lo que determina la aparición de habilidades extraordinarias (musicales, memorísticas, visuales, lingüísticas), en personas en las que la ceguera, sordera, demencia o discapacidad intelectual desactivan unas áreas, liberando otras.

En Los ojos de la mente (20I I), Sacks estudia varios casos de personas cuya capacidad visual se ha visto afectada. En los casos analizados de ceguera adquirida sorprende la plasticidad a la hora de adaptarse a la nueva situación, inconcebible desde la definición de discapacidad como pérdida y privación.

Llama la atención el caso de John Hull, profesor de religión en Inglaterra que, tras quedarse ciego experimentó la desaparición gradual de la imaginería y la memoria visuales hasta llegar a un estado que denominó “ceguera profunda", llegando a desaparecer la propia “idea” de ver. Hull consideró esta pérdida como un prerrequisito para su pleno desarrollo y potenciación de otros sentidos (como el oído), entregándose a su ceguera de forma mística, llegando a alcanzar una intimidad con la naturaleza y una intensidad en su estar en el mundo superior a todo lo que había conocido.

Sacks relata las experiencias de personajes célebres que encontraron fuerza creativa e identidad en la ceguera. Es el caso de John Milton, que meditó sobre cómo una visión interior puede ocupar el lugar de la visión exterior. Por su parte, Jorge Luis Borges escribió sobre los variados y paradójicos efectos de su ceguera y se preguntaba lo que debía de sentir Homero, que al quedarse ciego adquirió una idea de tiempo mucho más profunda y, con ello, una capacidad épica incomparable.

Explica Oliver Sacks cómo los neurocientíficos cognitivos han descubierto que el cerebro está mucho menos integrado de lo que se pensaba. Por ejemplo, en personas sordas de nacimiento, las partes auditivas del cerebro permanecen activas pero con una actividad y una función nuevas. Con la reasignación de partes de la corteza visual, el oído, el tacto y los demás sentidos de los ciegos pueden potenciarse de formas que una persona que ve no puede imaginar. Bernard Morin, matemático que demostró que se podía dar la vuelta a una esfera, quedó ciego a los seis años y consideraba que su descubrimiento precisaba de un tipo de visión espacial que ningún vidente podía tener. Un don táctil especial fue fundamental para el trabajo de Geerat Vermeij, ciego desde los tres años, que describió nuevas especies de moluscos basándose en las pequeñas variaciones de sus conchas.

Al parecer, no existe una experiencia "típica" de la ceguera. Muchos ciegos no sólo no pierden sus recuerdos de imágenes visuales, sino que incluso fabrican imágenes mentales de lo que les rodea. Es el caso del psicólogo Zoltan Torey, que tras quedarse ciego desarrolló al máximo su visión interior y su capacidad de imaginería visual, construyendo un mundo visual virtual tan real e intenso como el perceptivo que había perdido. Su imaginería visual le permitía pensar de una manera que antes no le era posible, como proyectarse en el interior de máquinas y otros sistemas e idear soluciones, modelos y diseños. Otro caso interesante es el de Sabriye Tenberken, que transformó la situación de los ciegos en el Tíbet, donde siempre habían sido discriminados. A pesar de quedarse ciega a los doce años, utilizaba sus otros sentidos, junto con descripciones verbales, recuerdos visuales y una gran sensibilidad sinestésica y pictórica 
para construir "cuadros" de escenas, no siempre ajustadas a la realidad, ya que la suya era una imaginación artística. Por su parte, Jacques Lusseyran, combatiente de la resistencia francesa, se adaptó a la ceguera desde los ocho años de edad, construyendo un mundo visual imaginario; su mente construyó una pantalla sobre la que proyectar y manipular lo que pensaba o deseaba.

La conclusión de Sacks es que cuando la corteza visual no se ve constreñida por ninguna entrada visual se vuelve hipersensible a estímulos internos: su propia actividad, señales de otras áreas del cerebro (auditivas, táctiles y verbales), así como pensamientos, recuerdos y emociones. De hecho, cada vez hay más pruebas de interacciones entre las áreas sensoriales del cerebro, por lo que resulta difícil decir que algo sea puramente visual o puramente auditivo o puramente olfativo o puramente táctil y, según parece, el mundo de los ciegos es especialmente rico en estadios intermedios para los que ni siquiera se dispone de términos descriptivos.

\section{Conclusión}

Como hemos mostrado en las páginas que anteceden, existe gran diversidad de maneras de percibir la realidad y de relacionarse con ella en función de factores históricos, culturales y personales.

Esto nos lleva, por una parte, a reparar en que, en cierto modo, todos somos "discapacitados" en cuanto que, al pertenecer a una cultura y a una época, hemos sido limitados y condicionados para percibir la realidad de determinada manera en detrimento de otras. Por ello, este texto es una invitación a trascender los límites de lo que nos ha sido inculcado como perceptible y real para así desarrollar nuevas "capacidades" o, al menos, una invitación a tomar conciencia de esta problemática.
Asimismo, hemos constatado que al etiquetar a un colectivo como "personas con discapacidad", se homogeneíza y generaliza la condición y situación de un colectivo imponiéndole una etiqueta que se traslada a su personalidad entera y que los convierte en portadores de un cuerpo no legítimo, mediocre, por debajo de las posibilidades fisiológicas de los seres humanos "normales".

Por ello, nos parece defendible la noción contemporánea de "diversidad funcional", que procede del propio colectivo de los etiquetados como "personas con discapacidad", que intentan reconocerse por lo que son y no por aquello de lo que supuestamente carece su cuerpo no normalizable, superando tanto el modelo médico-rehabilitador -que considera que la discapacidad reside en un sustrato fisiológico deficiente- como el modelo social -que evidencia las condiciones sociales que conforman la experiencia de la discapacidad. El concepto de diversidad funcional, en vez de partir de la insuficiencia, parte de una originalidad potencialmente creativa y enriquecedora. Al eludir la problemática de las capacidades, conceptualiza el fenómeno en términos de una singularidad funcional en el desenvolvimiento, apuntando así a la riqueza de la diversidad.

Para que la discapacidad deje de ser percibida como una enfermedad, con todas las connotaciones negativas que esto trae aparejado, se hace necesaria una nueva forma de concebir la salud, a saber: la capacidad de instaurar nuevas normas en situaciones adversas. Como hemos mostrado, atendiendo a la prodigiosa plasticidad del cerebro y a las experiencias de personas comúnmente concebidas como "discapacitadas" según una estrecha definición histórica y cultural de lo que es normal y funcional, podemos reivindicar el valor de la singularidad de cada forma de existir y percibir, y el respeto por la inmensa riqueza de lo humano en todas sus formas y modos de sentir. 


\section{Referencias bibliográficas}

Abberley, P. (I987): “The concept of opression and the development of a social theory of disability". Disability, Handicap \& Society, 2: 5-19.

Alvarez-Uría, F. y Varela, J. (1989): Sujetos frágiles. Ensayos de Sociología de la desviación. Madrid: FCE.

Barnes, C. (I991): Disabled People in Britain and Discrimination. Londres: Hurst \& Co.

Baudrillard, J. (2002): Cultura y simulacro. Barcelona: Kairós.

Berger P. L. y Luckmann T. (2003): La construcción social de la realidad. Buenos Aires: Amorrortu.

Bourdieu P. (I986): "Notas provisionales sobre la percepción social del cuerpo", en Alvarez-Uría, F. y Varela, J. (eds.): Materiales de sociología crítica. Madrid: La Piqueta: I83-194.

Le Breton, D. (2007): El sabor del mundo. Una antropología de los sentidos. Buenos Aires: Ed. Nueva Visión.

Canguilhem, G. (I970): Lo normal y lo patológico. Buenos Aires: Siglo Veintiuno Argentina Editores.

Classen, C. (1993): Worlds of sense. Exploring the senses in history and across cultures. London: Routledge.

Debord, G. (2005): La sociedad del espectáculo. Barcelona: Pre-textos.

Ferrante, C. y Ferreira, M.A.V. (20I I), “Cuerpo y habitus: el marco estructural de la experiencia de la discapacidad". Intersticios. Revista Sociológica de Pensamiento Crítico, 5 (2): 85-IoI.

Ferrer, C. (2000): Mal de ojo. El drama de la mirada. Barcelona: Octaedro.

Finkelstein, V. (I980): Attitudes and Disabled People: Issues for Discussion. New York: World Rehabilitation Fund.

Foucault, M. (2000): Vigilar y castigar. Madrid: Siglo XXI.
Foucault, M. (I999): El nacimiento de la clínica. Una arqueología de la mirada médica. Madrid: Siglo XXI.

Foucault, M. (1996): Tecnologías del yo y otros textos afines. Barcelona: Paidós.

Foucault, M. (I992): Genealogía del racismo. Madrid: La Piqueta.

Fox Keller, E. (1989): Reflexiones sobre género y ciencia. Valencia: Edicions Alfons el Magnànim.

Goffman, E. (2003): Estigma. La identidad deteriorada. Buenos Aires: Amorrortu.

Habermas, J. (1989): Ciencia y técnica como ideología. Madrid: Tecnos.

Illich, I. (I989): $\mathrm{H}_{2} \mathrm{O}$ o las aguas del olvido. Madrid: Cátedra.

Illich, I. (I975): Némesis médica. La expropiación de la salud. Barcelona: Barral.

Iranzo Amatriain, J.M. (2OI I): “'Toda enfermedad es un problema musical, toda cura es una solución musical' (Novalis). Una mirada sociológica sobre la obra de Oliver Sacks", Intersticios. Revista Sociológica de pensamiento crítico, 5 (2): 333-356.

Lizcano, E. (2006): Metáforas que nos piensan. Sobre ciencia, democracia y otras poderosas ficciones. Madrid: Traficantes de sueños.

Merleau-Ponty, M. (I986): El ojo y el espíritu. Buenos Aires: Paidós.

Merleau-Ponty, M. (1984): Fenomenología de la percepción. Barcelona: Planeta.

Merleau-Ponty, M. ( I970): Lo visible y lo invisible. Barcelona: Seix Barral.

Oliver, M. (1990): The Politics of Disablement. London: The MacMillan Press.

Ong, W. (I97I): Oralidad y escritura. Tecnologías de la palabra. FCE: México D.F.

Rodríguez Díaz, S. (20I2): Modernidad y cambio de valores: el caso del tabaco. Alemania: EAE. 
Rodríguez Díaz, S. y Ferreira, M.A.V. (20I0): "Desde la dis-capacidad hacia la diversidad funcional. Un ejercicio de dis-normalización”. Revista Internacional de Sociología, Centro Superior de Investigaciones Científicas (CSIC), 68: 289-309.

Rodríguez Díaz, S. y Ferreira, M.A.V. (2008): "Diversidad funcional: sobre lo normal y lo patológico en torno a la condición social de la dis-capacidad". Cuadernos de Relaciones Laborales, 28 (I). Universidad Complutense de Madrid: $64-85$.

Romañach, J. y Lobato, M. (2005): Diversidad funcional, nuevo término para la lucha por la dignidad en la diversidad del ser humano. Foro de Vida independiente.
Sacks, O. (20I I): Los ojos de la mente. Barcelona: Anagrama.

Simmel, G. (1977): "La metrópolis y la vida mental”. Revista Discusión, 2. Barcelona: Barral.

Turner, B. S. (1984): El cuerpo y la sociedad. Exploraciones en teoría social. México: Fondo de Cultura Económica.

Vigarello, G. (2006): Lo sano y lo malsano. Historia de las prácticas de la salud desde la Edad Media hasta nuestros días. Madrid: Abada.

Vigarello, G. (I991): Lo limpio y lo sucio. La higiene del cuerpo desde la Edad Media. Madrid: Alianza Editorial. 